\title{
Banking and Value Creation in Emerging Market
}

\author{
Kaies Samet \\ Faculty of Economic and Management Sciences of Sfax, Sfax University, Tunisia \\ Road of Gremda, km 0,5, Complex “Medina Center", Block A, $1^{\text {st }}$ stage, Ap.10, 3027 Sfax, Tunisia \\ Tel: (216)-99-331-303 / (216)-25-331-303Ｅ-mail: Kaies.Samet@fsegs.rnu.tn
}

\begin{abstract}
Tunisia has known an important technological progress in several fields, in particular in the banking sector, which was affected by reforms aiming to modernize it in order to make it adapted to the essential economic changes that the banking environment in all over the world is witnessing.

In this context, the reconciliations between banks were accentuated in the whole world, in particular in Tunisia (For example the merger by takeover of the BDET and the BNDT by the STB, which will constitute our practical case), since they realized that mergers constitute a useful means to face foreign competition, and thus to face globalization.

However, the most important thing for banking mergers is to know whether they create an added value for the banks concerned with the merger operation and for their shareholders. In our practical work, we find that in the case of Tunisia, results are not consistent with the theory in the short and mid runs. However, this last result will not have to discourage the operations of bank reconciliation, particularly banking merger, considering the context of globalization.
\end{abstract}

Keywords: Banking merger, Value creation, Ex-ante study, Ex-post study

\section{Introduction}

The growth of the companies results from the increase of investments that they carry out in time. This growth can be made in two ways:

- The first way is directed towards an internal development: development of the new products, of new distribution networks, installation of new production, extension of factories, ...

- The second way is directed towards modes of external growth, characterized by repurchases of companies, mergers, alliances,...

The choice between these two ways of growth, internal and external, constitutes for the company a strategic choice of great importance and conditions the circumstances and the speed of its development.

During the Nineties, there was a considerable development of the operations of external growth. However, in our framework, we are interested only in operations of banking merger, a phenomenon which did not cease accelerating during these two last decades. The growth of this phenomenon involved deep structural upheavals of this sector and in the industry of the financial services in general, in the industrialized countries as well as in certain emergent countries.

In Tunisia, the phenomenon of banking merger does not present the same width as that observed in the industrialized countries, with only two merger plans carried out between tunisian banks: the first one, which is very old, was implemented between the BNDA (Note 1) and the BNT (Note 2) giving rise to the BNA (Note 3), whereas the second one was concretized few years later, consisting in a merger by takeover of the BDET (Note 4) and the BNDT (Note 5) by the STB. (Note 6)

It should be noted that the adoption of a particular position with respect to this form of growth by the Tunisian banks remains a difficult operation considering the complexity of its procedures of installation, the diversity of its targeted aims, the importance of its effects and especially the lack of revealed information relating to it.

It is obvious that mergers in the banking sector and elsewhere absorb considerable amount of time and talent of the leaders. Since these mergers generally require enormous capital, it is absolutely imperative to know if all this time and all this money are really spent wisely or, in other words, what these mergers bring to the economy. It is within this framework that we inquire if mergers between the financial institutions create or destroy the value? In other words, following the announcement of the operation, will we witness an increase in the wealth of the shareholders of the concerned companies as well as an improvement of their performance or is it going to be the opposite? And according to these results, should we encourage or discourage these reconciliation operations? Each bank must be able to find its way and to develop its own strategy to position itself on the local market as 
well as the international market. Thus, it is important to study the banking strategies and to see which strategies could be applied in the Tunisian bank of tomorrow? Among these strategies, we can evoke banking mergers.

\section{Banking merger}

\subsection{Merger: Definition and its various types}

It is an operation by which several companies are combined to form only one, thus losing their independence according to the agreement reached.

Economically speaking, merger has the aim of joining together in only one economic entity the whole means available for the amalgamating firms (financial resources, personnel, material of production,...), to achieve strategic goals.

By resorting to practical facts, we can distinguish 3 types of merger:

- Horizontal merger: two rival companies merge or join together;

- Vertical merger: generates the integration of two firms which could only maintain simple contractual relations of customer with supplier;

- Conglomeral merger: when two companies amalgamate whereas they provide different goods.

In addition, we can distinguish two forms of merger (Note 7) namely:

- Merger by takeover: it is the operation by which a company transfers to another, as a consequence of dissolution without liquidation, all its assets and liabilities heritage, on condition that providing for the shareholders of the absorbed company of the absorbing company shares. This operation is differently analyzed for the acting firms of the merger:

For the absorbing company: Merger results in an increase in the capital with contributions in nature. Hence, the need to go by the determination of the share marketable value before takeover and of the number of securities to transmit in return of the contribution of the absorbed company;

For the absorbed company: Merger is analyzed on the one hand like a liquidation, and on the other hand like a sharing with the attribution of the shares or the securities created by the absorbing company with the former partners of the absorbed company. Hence, the need for the determination of the company value or the net contribution after readjustment of assets and liabilities elements according to the methods of takeover.

- Merger by creation of a new company: it is an operation in which old companies disappear by means of dissolution, making total contribution of their assets and liabilities situation for the benefit of a new moral person. This operation is analyzed:

$>$ for the new company in a constitution with contribution in nature;

$>$ for the old companies in a liquidation and a sharing with attribution of the securities or the shares of the new firm for the partners of the disappearing companies.

\subsection{Main characteristics of the mergers and acquisitions banking movement}

They are 4, namely:

- A really universal movement;

- An accelerating movement: the involved amounts do not cease increasing from year to year, passing for example from 17 billion dollars in 1995 to 350 billion dollars in 1998. In the same way, the number of the operations is highly increasing;

- Strong preponderance of the domestic operations in the banking reorganizations: which is completely logical because the lawful, tax and cultural divergences (culture of company) were opposed to a fuller internationalization of the operations; and

- A polarization of the operations in commercial banks.

\subsection{Key factors for the success of the mergers and acquisitions banking operations}

Since the operations of mergers and acquisitions include potentially significant costs, the attention is then given to the conditions of success of these operations. Among these conditions, we can distinguish:

- The realization of the merger in a short time from 9 to 12 months;

- The strategic intention: "Above all, he must make sure of logical strategy of the operation that he's thinking about. My second advice is to check that the partner really shares this strategic vision"; (Note 8) 
- Make it simple, even "rustic", then optimize after merger;

- The management of post-acquisition integration: this criterion is decisive for the success of the operation. Three years after merger, the operations which appeared as real successes increased the value for the shareholder during that period.

The integration assumes a thorough analysis of the consequences, which must be carried out before the operation itself. It also supposes a rigorous and detailed planning of the whole steps having to lead to the operational integration of the activities. Lastly, it supposes a good apprehension of the difficulties of operation;

- The cultural and human dimension: the culture of a company constitutes an essential competitive advantage for the latter. Indeed, the comprehension of the culture of the partner must make it possible to prevent the conflicts and to better measure the difficulties that may arise from merger.

Concerning the human capital management, previous experience proves that it must be taken into account as an important part of the process;

- Avoid making an "addition" merger: mergers also aiming at making economies of scale a significant part of these economies, in particular at the level of the staff, must be obtained as of merger;

- Make the personnel take part and largely involve them: many tasks are to be realized in a merger; and it is necessary to gear down at the earliest time the teams to distribute the charges and to create information and training relays for the personnel; and

- To pass by two great phases: it is initially important to reflect and to globally conceive, then to throw all actions with a clearly designated person in charge.

\subsection{Reasons for mergers between banks}

The reorganization and the modernization of the banking structure are of a crucial interest for the economic development. The arguments of those who are in favour of current mergers and acquisitions seem rather convincing concerning the benefits to expect from these mergers, which would always exceed their momentary disadvantages.

A deeper examination of the quantified facts and results, some time after the effective realization of the operation, shows that the expected results are not always up to the expectations of these optimistic predictions. The results of works on banking mergers, both theoretical and empirical, showed the existence of economies of scale and range as well as of profits from productive effectiveness and/or effectiveness-profit. These two factors partly explain the reasons for mergers between banks.

The third factor which explains the reasons for banking mergers is competition. Indeed, following the deregulation, the innovations and the implementation of new technologies, competition has significantly grown in the banking sector of which return worsened in a correlative way.

The shareholders also became more requiring. The leaders are then obliged to restore their return by reducing these competing pressures, which require a certain mastery of some power over the market. Therefore, the research of the capacity of the market constitutes another explanatory factor of merger between banks.

\subsection{Motivations of banking merger}

The motivations which pushed the banks to be amalgamated are numerous, among which we can enumerate the following factors:

\subsubsection{A more complex and heterogeneous competition}

Insurance companies could represent an important competitor for the banks. Their competences as regards the appreciation of the risks related to the continuity of the relation with their customers and the volume of information that they hold should encourage them to claim the access to the loan activity, in order to supplement their financial service and line of goods for both the companies and the private individuals.

The banks adapt to this new competing framework by adopting more sophisticated forms of organization by, for example, resorting to the means of external growth such as merger. Merger thus seems to be a defensive reaction vis-à-vis the intensification of competition between banks.

\subsubsection{Motivations of a commercial nature: diversification and risk reduction}

Banking merger makes it possible to decrease the risk by diversifying it.

\subsubsection{Motivation related to the complementarity of skills between banks}

For this reason, merger will allow the banks going through merger to share specific competences of each partner, in order to develop new products and services. The pooling of competences is effective in the development 
and/or the distribution of the products and banking services, if one of the partners has the control of several functions or a good knowledge of the various segments of the customers. Indeed, the bank will be able to release more quickly economies of range, owing to the fact that the acquired firm is already specialized in this new activity, which will have as a consequence the lowering of the training cost.

\subsubsection{Motivation related to the distribution of the products on a grand scale}

The search for economies of scale in the banking sector intervenes mainly at the level of distribution, by the use of common networks of several partners. It allows the banks which are deprived of a network to quickly reach the establishments having a network and therefore to reduce the cost of implementation.

Indeed, with this mode of growth, which is merger, the bank will immediately obtain a market share as well as the access to customers funds which can cause a defect in certain banking activities (for example, the granting of financings for the customers), which constitutes a saving of time compared to a process where it would have been necessary to build a new network of agency (internal case of growth).

This motivation is at the heart of the agreements between the banks with networks and certain specialized banks without network on the one hand, and between the banks and insurance companies on the other hand.

\subsubsection{Motivation related to the installation of a training process between partners}

The merger strategy can be regarded as the expression of the will of the partners to diffuse and join together their knowledge in order to develop a training process. These relations promote the access to additional knowledge and allow the development of new activities (like the bank insurance), in which certain banks could never have engaged alone.

The personnel becomes more and more experienced, which makes it possible to develop productivity profits, which on their turn contribute to improve the competitive position of the bank and to support its subsequent power.

\subsubsection{The deregulation and the desintermediation of the markets}

The process of deregulation and modernization of the financial spheres has indeed modified the contents and the environment of banking activities. For example, the evolution of leasing and finance companies led to the desintermediation, a phenomenon according to which the banks lose their traditional role of intermediary between the lenders and the borrowers.

This tendency promoted the banking reconciliation, in order to consolidate their positions on the market against new entries.

\subsubsection{The value creation}

Merger between two establishments makes it possible to exploit synergies, and consequently to increase the profits by a decrease of the costs or an increase in the incomes. The reduction in the costs can be obtained by:

- the elimination of duplicates in the amalgamated entities: the presence of two identical services or functions which carry on the same activity within the new establishment generates additional costs, of which it is necessary to leave just one service by gathering the two entities in only one or by creating a new one;

- the reduction of personnel: it's noticeable that several banks present, following the merger operation, plethoric manpower from which only the qualified personnel should be kept. This overstaffing presents an overcost for the new bank which will be able to have an influence on its short and long run results;

- the rationalization of the networks: for the closing of the network which does not give any added value for the bank; and

- the realization of economies of scale by the exploitation of the new partners' networks.

The value creation is an objective sought by any merger operation. This fact rises even from the significance of the term "synergy", which indicates "the consecutive supplement of value for an amalgamation of firms which can be only obtained by the effective realization of the amalgamation".

\section{Banking merger and value creation in the Tunisian case}

The study of the relation between the merger and the value creation is complex. At this level, there is a conflict between two large schools:

- The first school, referring to the agency theory, highlights the role of the market of companies' control (by the materialization of merger operations) as an external mechanism of control of the agency relation. The merger operations are clear value creators. 
- The second school, starting with a widening of the agency theory to the whole recipients which are important for the life of the company and the contributions of the rooting theory, opposes a diagram in which, from the point of view of the purchaser, merger is a means for the leaders to pursue their goals (growth of the capacity, reduction of risks, ...).

At the banking level, it was proved, according to various studies, that merger creates value: the shareholders of the target companies carry out considerable appreciations contrary to those of the purchasers who take a weak and even a null benefit from this operation.

In this case, if the accumulated empirical work recognizes the existence of a clear value creation for the shareholders, especially for the shareholders of the target, can we conclude that these merger operations are value creators? In other words, can one limit the analysis to the taking into account of the interests of the shareholders? The answer is negative. Indeed, with regard to the performance of the banks concerned with merger, it was degraded.

The fact that banking mergers result could be translated in short run in significant profits for the shareholders of the targets and that in long run, the shareholders of the initiating firms of these operations are losers, raises many questions:

1) Why do the leaders, who are supposed to act for the interest of their shareholders, launch out such operations which certainly enrich the shareholders of the target firms? This question is directly related to the agency paradigm.

Concerning the answer to this question, we can say that the results of the empirical research, with regard to the mergers and acquisitions operations, can be interpreted in various ways:

- For certain authors, they constitute a manifestation of the inefficiency of the markets which would be unable to correctly anticipate the profits related to mergers and acquisitions, especially over a long period;

- For others, in the agency theory, it is about a demonstration of the divergence of interests between the leaders of the purchasing firms and their shareholders.

2) According to what preceded, should these mergers and acquisitions operations be slowed down or encouraged? In other words, one will wonder about the utility of these operations. Indeed, null return, even negative, for the shareholders of the initiating companies, is likely to decrease competition with the appearance of giant firms as well as a negative impact on employment, at least in short run. It is because of these short run negative aspects of the mergers and acquisitions operations that the largely widespread opinion in the public is to slow down these operations.

By promoting the emergence of oligopolies, even of monopolies, mergers are not also well seen from the point of view of the consumers, who fear a diminution of competition and an increase of sale prices.

In spite of these criticisms and fears, the market of mergers and acquisitions develops. This development is mainly explained by the phenomenon of globalization. Indeed, it is obvious that banking merger is a phenomenon which is very widespread in the European countries and the United States, but which is it less widespread in Tunisia for the above mentioned reasons.

Within this framework, on the Tunisian money market, we saw concretizing these last years a merger plan between the BDET, the BNDT and the STB. This last will be the object of our study in what follows, where we will try to check the released results from the literature by using both the direct and the indirect methods of evaluation.

\subsection{Presentation of merger-takeover STB-BDET-BNDT}

\subsubsection{Economic aspects of the operation}

In our practical work, we will take merger by takeover of the BDET and the BNDT by the STB.

\subsubsection{Pre-existent bonds in capital (on 31/12/1999)}

See table 1.

At the date of the signature of the merger treaty, there were no more reciprocal participations between the three banks. The entire securities STB, BDET and BNDT held by the three banks were yielded on the stock exchange market.

\subsubsection{Common participation between the three banks (\%)}

See table 2 .

2.1.1.3 Goals and reasons for the strategy 
The aim of the merger strategy between the STB, the BDET and the BNDT is to give to the Tunisian banking structure a new dimension and to equip it with a more consequent competitive capacity, thanks to a better efficiency and to a greater synergy of the means and competences.

Within the framework of the new Tunisian banking system requirements, this movement of merger is an answer adapted to the desintermediation and the deregulation for the banks, which want to consolidate their financial capacities to be more competitive and to have a suitable size and to develop a sufficient proximity network.

The motivations of this merger are numerous. The first motivation is economic. In fact, the reality increasingly imposes an important size in terms of assets or market capitalization, in order to maintain presence on the markets.

Secondly, given the development of the new means of communication and the technological distribution, the economies of scale can appear necessary especially in front of the rise of the investment means and the need for additional volume of treatment, in a context of drop oriented incomes.

2.1.2 Legal and tax aspects of merger

\subsubsection{Dates of approval of the merger principle}

The merger principle of the three banks was adopted by their respective extraordinary general meetings (EGM), that is to say the 15/7/1999 for the BDET, the 29/7/1999 for the BNDT and the 4/9/1999 for the STB.

\subsubsection{Closing date of the accounts retained for the realization of merger}

The accounts retained for the realization of merger are those of the 31/12/1999, such as decrees by the boards of directors $(\mathrm{BD})$, certified by the statutory auditors and approved by the ordinary general meetings of the three banks.

\subsubsection{Effect date of the merger}

Merger would have a retroactive effect on January the first, 2000. Consequently, the operations carried out by the absorbed companies as from the 1/1/2000 and until the final date of merger will be regarded as being made on behalf of the absorbing company. The STB was committed to take the charge of the commitments adhered by the absorbed companies until the date of the realization of the merger.

\subsubsection{Date of the signature of the merger treaty}

The chairmen and managing directors of the three banks, joined together on the 26/9/2000, signed the merger treaty laying down the methods of the operation, which were then published in an official statement for information of the public. The formula selected is that of a merger-takeover, in which the STB takes over the BDET and the BNDT.

\subsubsection{Dates of the approval of the merger by the boards of directors of the banks}

The merger treaty was approved by the board of directors of each company, brought together respectively:

- 16/10/2000 for the STB;

- 18/10/2000 for the BDET; and

- 19/10/2000 for the BNDT.

\subsubsection{Approval of the merger operation}

The extraordinary general meetings had to approve the operation on the following dates:

- 8/12/2000 for the BDET;

- 18/12/2000 for the BNDT; and

$-21 / 12 / 2000$ for the STB.

After these approvals, the merger became final.

2.1.3 Evaluation of the banks and determination of the exchange parities

See Table 3. We extract the following exchange parity: 1 BDET share $=0,6411$ STB shares. (Note 12)

See Table 4 . The result is the following exchange parity: 1 BNDT share $=0,4112$ STB shares. (Note 13)

These parities would become effective only after their approval by the extraordinary general meetings of the three banks concerned. After approval, these meetings would be convened within the prescribed deadlines to deliberate on this plan, which could be concretized before the end of the year by January the first 2000, as the effective date for the merger.

2.1.4 Determination, evaluation and accounting of the contributions

The BDET and the BNDT bring to the STB, within the framework of this operation in question, all the elements (assets and liabilities), rights and values belonging to them which constitute their entire respective heritage without 
exception or reserve. This enumeration has only an indicative and not a restrictive aspect: the heritage of the BDET and the BNDT must be rendered on a purely universal basis to the STB, at the date of the realization of merger.

The assets and the liabilities ones were brought on the basis of their net book value on the $31 / 12 / 1999$, as they appeared in the financial statements of the BDET and BNDT companies, approved by their respective general meetings and reduced amounts of the dividends and percentages adopted by these same meetings and distributed in the year 2000.

In sum, the net contribution of the BDET to the STB was stopped at 103,491 million dinars, whereas that of the BNDT to the STB was stopped at 82,160 million dinars.

In remuneration of the contributions analyzed above, the shareholders of the absorbed companies (BDET and BNDT) would receive shares of the absorbing company (STB) calculated according to terms of trade rising from the study on evaluation of each of the three banks. The difference between the contribution value and the face value of the shares to be emitted by the absorbing bank constitutes the merger premium, which would be accounted in the liabilities of the balance sheet of the absorbing company and would belong to all the old and new shareholders.

\subsubsection{Presentation of new bank (New STB)}

The year 2000 was characterized by the concretization of the plan of merger by takeover of the BDET and the BNDT by the STB. This great event in the history of the Tunisian economy marked a new configuration of the structure of the Tunisian banking system and opened the way to other merger operations, while giving to the STB a competing advantage and an important dash of growth.

The adoption of the BDET and the BNDT by the pioneering deposit banks in Tunisia gave rise to the first national bank with a universal vocation, equipped with a more consequent competitive capacity thanks to a better efficiency and a greater synergy of means and competences. It associated the activities of a commercial bank with those of a development and merchant bank, and held a capital of 124,3 million dinars.

The STB, in its new form, occupied thereafter, by the total of its equity capital and that of its assets, the first rank in the Tunisian banking environment and the fourth in North Africa. This new dimension conferred to the STB a better positioning, in both the granting of loans to the Tunisian economy and the collection of resources, and allows it to take up the challenges of globalization. Within this framework, the bank reinforced its action for the promotion of new plans, and the financing of the productive investment for a better combination of the synergies generated by the complementarities of competences and activities. In this context, the activity deployed by the STB, during 2000, evolved favourably allowing a development of the principal indicators of growth.

The new bank would combine, in addition to its vocation as a universal bank, the development of its retail banking competences by proposing a broad pallet of services to the customers of the companies and private individuals (thanks to its vast network of exploitation, and the adoption of a marketing strategy focusing on the development of its products and its services), as those of a wholesale banking offering to the specialized organizations and the business groups the funding, the skills and the professionalism of its teams. It would also be able to develop the technological supports of communication and distribution.

The bank adopted a new form of governorship at the time of the extraordinary general meeting of February 3, 2001. Indeed, the installation of a supervisory board and a directory, which dissociates the control from the management, ensures a better defense of the interests of the shareholders and makes it possible for the managers to be fully devoted to the achievement of performance objectives.

The future orientations of the "new STB" would be centered on:

- the development of the functions of a retail banking, development bank, merchant bank and the banking correspondent;

- the control of new technologies as a tool allowing to reinforce range of customers and to improve the quality of the services (speed, facility, weaker cost,...);

- the looking for the best level of service to the customers by a broad range of products, diversified channels of distribution and a thorough knowledge of the market products;

- the development of the new generating activities of increased incomes.

The fact of acquiring a company, financial or non-financial, is to make an investment. The entire question is to know if this investment, materialized by the operation of merger by takeover of the BDET and the BNDT by the STB, would create a value, in particular for the latter, at the level of its shareholders as well as the level of its performance? In other words, is it a profitable investment? (Note 14) 
There are several methods which make it possible to evaluate the effects of mergers, but two among them stand out since they have helped out in several applications. We find:

\subsection{Ex-ante study}

It endeavours to evaluate the performance of merger in an indirect way, by analyzing the reactions of the stock market to the announcement of merger. This study is called "the event study". In our case, the event is the announcement of merger.

In order to evaluate the total effect of the event on the wealth of the shareholders, we calculate the average of the abnormal yield (AY) or the cumulative average abnormal return (CAAR), over one period of observation called "window of events".

\subsubsection{Presentation of the sample of study}

In addition to the STB, our sample of study is composed of the other deposit banks of the place like Amen Bank, ATB (Note 15), BH (Note 16), BIAT (Note 17), BNA, BS (Note 18), BT (Note 19), UBCI (Note 20) and UIB (Note 21). This choice is justified by the fact of knowing if the realization of the merger operation influenced the evolution of the share prices of the latter, not concerned with this operation.

\subsubsection{Model of study}

The calculation of the theoretical yield is done according to the CAPM (Note 22) or the MM (Note 23). In our study, we chose to use the MM, because the independent variable is the market yield (in our case, TUNINDEX index) which is daily calculated and published by the TSE (Note 24), whereas the CAPM presents multiple calculations for the determination of the systematic risk of the security, especially with our sample which is composed of 10 securities.

In our case, the MM, as defined by Sharpe (1963) within the framework of a linear relation between $R_{i, t}$ and $R_{m, t}$ (RT), is as follows:

$$
\mathrm{R}_{\mathrm{i}, \mathrm{t}}=\alpha_{0}+\beta \mathrm{RT}+\varepsilon
$$

$$
\left\{\begin{array}{l}
\mathrm{R}_{\mathrm{i}, \mathrm{t}}=\text { Yield of security } \mathrm{i} \text { at the moment } \mathrm{t} \\
\beta \quad=\text { Sensitivity coefficient of the securities or systematic risk coefficient; } \\
\mathrm{RT}=\text { TUNINDEX yield; and } \\
\varepsilon \text { follows a normal law }\left(0, \sigma^{2}\right)
\end{array}\right.
$$

Since it is a question of studying the impact of the merger operation in question, it is necessary to bear in mind two periods: the ante-merger period and the post-merger period. For this reason, it is necessary to integrate in our model the variable "Period" $(\mathrm{P})$. So, the following model of study will be presented as follows:

$$
\mathrm{R}_{\mathrm{i}, \mathrm{t}}=\alpha_{0}+\beta \mathrm{RT}+\alpha_{1} \mathrm{P}+\varepsilon
$$

\subsubsection{Choice of the date and the period of study}

The settlement of the date of merger operation was at the origin of several controversies between the authors. Some consider that it coincides with the date of first public announcement, while others make it correspond to the date of its effective realization.

In our study, we chose the second alternative, since it is very difficult to exactly specify the first date. This date is the $21 / 12 / 2000$.

Thus, the period of study extends from the 2/1/1998 to the 31/12/2001.

\subsubsection{Results of the study}

The results released by using the EVIEWS software emphasize two major problems, namely:

- Non-significativity of the model; and

- the dependence between errors: Hypothesis of not-checked homoscedasticity.

To face the first problem, we introduced into our model another variable, which is R(-1): Delayed yield. The model becomes:

$$
\mathbf{R}_{\mathrm{i}, \mathrm{t}}=\alpha_{0}+\boldsymbol{\beta} \mathrm{RT}+\alpha_{1} \mathbf{P}+\boldsymbol{\beta}_{1} \mathbf{R}(-1)+\varepsilon
$$


The ARCH (Note 25) and GARCH (Note 26) models will be introduced to correct the problem of heteroscedasticity of the errors.

ARCH model was defined by Engle in 1982 as follows:

$$
\left\{\begin{array}{l}
\mathrm{Y}_{\mathrm{t}}=\varepsilon_{\mathrm{t}} \\
\text { with } \mathrm{E}\left(\varepsilon_{\mathrm{t}} / \varepsilon_{\mathrm{t}-1}\right)=0 \\
\text { and } \mathrm{E}\left(\varepsilon_{\mathrm{t}}{ }^{2} / \varepsilon_{\mathrm{t}-1}\right)=\mathrm{h}_{\mathrm{t}}=\mathrm{c}+\sum_{i=1}^{\mathrm{q}} \mathrm{a}_{\mathrm{i}} \varepsilon_{\mathrm{t}-\mathrm{i}}{ }^{2} ; \mathrm{a}_{\mathrm{q}} \neq 0
\end{array}\right.
$$

GARCH model was defined by Bollerslev in 1986 as follows:

$$
\left\{\begin{array}{l}
\mathrm{Y}_{\mathrm{t}}=\varepsilon_{\mathrm{t}} \\
\text { with } \mathrm{E}\left(\varepsilon_{\mathrm{t}} / \varepsilon_{\mathrm{t}-1}\right)=0 \\
\text { and } \mathrm{E}\left(\varepsilon_{\mathrm{t}}{ }^{2} / \varepsilon_{\mathrm{t}-1}\right)=\mathrm{h}_{\mathrm{t}}=\mathrm{c}+\sum_{i=1}^{q} \alpha_{\mathrm{i}} \varepsilon_{\mathrm{t}-\mathrm{i}}{ }^{2}+\sum_{j=1}^{p} \beta_{\mathrm{j}} \mathrm{h}_{\mathrm{t}-\mathrm{j}} ; \alpha_{\mathrm{q}} \neq 0 ; \beta_{\mathrm{p}} \neq 0
\end{array}\right.
$$

\subsubsection{Hypotheses Test}

$$
\left\{\begin{array}{l}
\mathrm{H}_{0}: \text { AY before merger }=A Y \text { after merger } \\
\mathrm{H}_{1}: \text { AY before merger } \neq A Y \text { after merger }
\end{array}\right.
$$

2.2.6 Decision rule

- If T-test $<5 \%$, the test is significant $=>$ Rejection of $\mathrm{H}_{0}$ (we accept $\mathrm{H}_{1}$ ). Consequently, the merger operation has an effect on the abnormal yield. This effect can be:

1) positive $=>$ Value creation for the shareholders of the concerned bank;

2) negative $=>$ Value destruction for the shareholders of the concerned bank.

- If T-test $>5 \%$, the test is not significant $=>$ Acceptation of $\mathrm{H}_{0}$. Consequently, the merger operation does not have any impact on the abnormal yield (No value creation for the shareholders of the concerned bank).

\subsubsection{Interpretation of the results of the study}

- On a sample of 10 banks, two only ("BH" and "BS") present a significant test with respective probabilities of 0,010463 and 0,031254 . But, their situation is different given that:

- The effect of merger is negative on the abnormal yield of the BH: this last has significantly decreased passing from 0,000466 before merger to $-0,001559$ after merger. Therefore, there was no value creation for the shareholders of the $\mathrm{BH}$;

- On the other hand, the merger has positively affected the abnormal yield of the BS, which has significantly increased from $-0,000404$ before merger to 0,00106 after this operation. So, there was value creation for the shareholders of the BS.

- For the other deposit banks, and particularly the STB author of the merger operation in question (i.e. the initiating company), the non-significativity of the test $(0,626949)$ leads us to conclude that there was no effect of the merger operation on the wealth of the shareholders of the STB. Therefore, there was no value creation for the shareholders of the STB.

- Therefore, in a word, we can say that only the shareholders of the BS benefited in short run from the operation of merger-takeover STB-BDET-BNDT.

\subsection{Ex-post study (Note 27)}

It aims at a direct evaluation, by analyzing the effects of mergers on the real performance of the company, as it can be measured starting from the internal accounting results.

Thus, at this level, we will be interested in the impact of the operation of merger by takeover of the BDET and the BNDT by the STB on the real performance of this last bank, while basing ourselves on the balance sheets before merger (1998, 1999 and 2000) and after merger (2001). 
Indeed, dealing with this merger by takeover operation, the analysis of the performance of the two development banks in question (BDET and BNDT) after merger cannot be realized. This is what justifies that we will proceed to analyze the impact of this merger operation only on the performance of the STB, while locating it compared to the other deposit banks of the market which are Amen Bank, ATB, BH, BIAT, BNA, BS, BT, UBCI and UIB.

Within this framework, we will carry out a financial analysis according to the following ratios:

\subsubsection{Ratio of return on sales (or net income ratio)}

This ratio measures the return on sales. It translates the total effectiveness of the company for its entire activities. It is given according to the following formula:

Net income ratio $=$ Net Profit $/$ Turnover

From the results obtained, we can note that after the merger operation (in 2001), and contrary to its situation before merger, the STB became commercially less profitable, since it recorded a light fall of its net income ratio passing from $16,77 \%$ in 2000 to $15,44 \%$ in 2001 . This fall, given by a decrease in its net profit of about $9,84 \%$, must be more important than the decrease in its turnover of 2,09\%.

With the decrease of its return on sales, the STB position worsened after merger, by occupying the $5^{\text {th }}$ place (whereas it occupied the $4^{\text {th }}$ place before merger, in 2000$)$ after BT $(25,78 \%)$, UBCI $(18,75 \%)$, Amen Bank $(17,58 \%)$ and $\operatorname{BIAT}(15,7 \%)$.

It results from what preceded that the merger had a negative impact on the return on sales of the STB.

\subsubsection{Ratio of return on assets}

This ratio measures the return on assets managed by the bank. It is determined by the relationship between the net profit (NP) and the total assets (TA).

According to the results obtained, we note that after merger, the STB recorded a fall in its return on assets passing from $1,2 \%$ in 2000 to $1,06 \%$ in 2001 . This variation is caused by a reduction in the net profit of about $9,84 \%$, which is more important than the increase in the total assets of $2,64 \%$.

This reduction in the return on assets of the STB in 2001 degraded its position compared to the other banks, passing from the $5^{\text {th }}$ place in 2000 to the $7^{\text {th }}$ place in 2001 , after BT $(2,08 \%)$, UBCI $(1,67 \%)$, Amen Bank $(1,47 \%)$, BIAT $(1,26 \%)$, BS $(1,19 \%)$ and UIB $(1,07 \%)$.

In sum, there was a negative effect of merger on the return on assets of the STB.

\subsubsection{Ratio of return on equity}

This ratio measures the return from the point of view of the owners who brought equity capital. It is determined by the relationship between the net profit (NP) and the equity capital (EC).

From the results found, we can notice that the return on equity of the STB continued to decline until reaching $10,82 \%$ in 2001.

After Amen Bank (19,95\%), BT (19,15\%), BIAT (17,16\%), UIB (16,44\%), UBCI (14,09\%), BH (12,91\%) and BS $(12,74 \%)$, we find the STB with a rate of return on equity equal to $10,82 \%$. The latter ranks the STB at the $8^{\text {th }}$ position, while in 2000 it had the $7^{\text {th }}$ rank. Consequently, this justifies the negative impact of merger by takeover of the BDET and the BNDT by the STB on the return on equity of the purchaser.

Just as for these measurements of return (on sales, on assets and on equity), the merger had a negative effect on the productivity of the initiating company STB, on both its equity capital (from 39,72\% in 2000 to $35,51 \%$ in 2001) and its invested capitals (from $3,67 \%$ in 2000 to $3,46 \%$ in 2001).

In a word, we can conclude that the operation of merger-takeover of the BDET and BNDT by the STB deteriorated the short run performance of the STB.

Concerning the mid run effect of this merger (i.e. by bearing in mind the years 2002, 2003 and 2004), and by considering for example the ex-post study, we can notice that the performance of the STB, both regarding return

and productivity, worsened more. Indeed, while moving from the period before merger (i.e. before 2001) to the period after this operation (i.e. after 2001), we can observe a decline of each rate of performance of the STB until reaching very low levels:

- from $16,77 \%$ in 2000 (the $4^{\text {th }}$ place) up to $2,1 \%$ in 2004 (or the $7^{\text {th }}$ place), for the ratio of return on sales;

- from $1,2 \%$ in 2000 (the $5^{\text {th }}$ place) up to $0,12 \%$ in 2004 (or the $7^{\text {th }}$ place), for the ratio of return on assets;

- from $12,99 \%$ in 2000 up to $1,26 \%$ in 2004 , for the ratio of return on equity; 
- from $39,72 \%$ in 2000 to $29,75 \%$ in 2004 , for the ratio of productivity on equity;

- and finally from $3,67 \%$ in 2000 up to $2,89 \%$ in 2004 , for the ratio of productivity on invested capitals, thus allowing the initiating company to occupy at this level the $10^{\text {th }}$ and last position compared to all the other deposit banks.

\section{Conclusion}

The investment made by the STB is not profitable in short and mid runs (No value creation), thus confirming the results of the literature. So, "what results can merger have on STB in the long run?" A question which could be examined later. This result will have to discourage banking mergers in Tunisia, unless contrary results with those found in short and mid runs will take place in the long run.

However, generally, these reconciliation operations between banks should be encouraged in Tunisia. Indeed, the future development of such operations of banking merger proves to be necessary and inevitable for Tunisia, which was expecting an intense and increased competition, considering the context of globalization.

Within this framework, it is necessary to make a success out of the merger operation, object of our previous interest, because it is a headlight operation, a testing operation for the continuation of the modernization, the adaptation and the reorganization of the Tunisian financial place.

\section{References}

\section{Articles}

Albouy, M. (2000). A qui profitent les fusions-acquisitions? Le regard du financier. Revue Française de Gestion, $131,70-84$.

Benefield, M. E. \& Perry L. G. (1996). Assessing the motivation of small banks and bank holdings companies in the acquisition of thrift institutions. Proceedings of the American Society of Business and Behavioral Sciences, IV, 226-236.

Black, E. L., Carnes, T. A. \& Jandik, T. (2001). The long-term success of cross-boarder mergers and acquisitions. Financial Accounting Working Paper Series.

Boyer, R. \& Freyssenet M. (2000). Fusions-acquisitions et stratégies de profits. Revue Française de Gestion, 131, 20-40.

Cheryl, F. \& Bruce Kavan, C. (2000). An examination of bank mergers activity: A strategic framework content analysis. Academy of Accounting and Financial Studies.

Egg, G. (2000). Fusion et gestion des ressources humaines : les principes plus importants que les outils. Revue Française de Gestion, 131, 108-113.

Metais, J. \& Michaud, L. F. Les méga-fusions bancaires et le dilemme efficacité-stabilité. Communication at the days of the AFSE Orleans, May 17, and 182001.

Mucchielli, J. \& Kohler P. (2000). Déterminants et conséquences des fusions-acquisitions. Revue Française de Gestion, 131, 6-19.

Pilloff, S. J. \& Santomero A. M. (1998). The value effects of bank mergers and acquisitions. Bank Mergers \& Acquisitions, eds. Kluwer Academic Publishers.

Schenk, H. (1996). Bandwagon Mergers, International Competitiveness, and Government Policy. Empirica, 23 (3), 255-278.

Thompson, J. P. (2000). A multiple metric study of the returns of shareholders: The case of bank holding company mergers - Part II, the source of the returns. Journal of Financial and Strategic Decisions, 13 (3).

\section{Magazines}

\section{- L'Economiste Maghrébin}

- $\quad$ Fusion-absorption STB-BDET-BNDT. Nous avons l'obligation de réussite, 281, 22-26.

- Le secteur bancaire tunisien est désormais préparé à la concurrence, 233, p. 24.

- Les banques tunisiennes à l'heure de concentration, 233, p.21.

\section{- Réalités}

Préserver la spécificité et provoquer des synergies, 719, 21-22.

\section{- Revue de la Banque}


- L'organisation des fusions bancaires, 6, July 1989.

- $\quad$ Fusion bancaire : réussir son personnel, 29, Mars/April 1996.

\section{Reports}

Annual report of the STB 2000.

\section{Web sites}

- www.bnacapitaux.com.tn

- www.bct.gov.tn

Notes

Note 1. Banque Nationale de Développement Agricole.

Note 2. Banque Nationale de Tunisie.

Note 3. Banque Nationale Agricole.

Note 4. Banque de Développement de l'Economie Tunisienne.

Note 5. Banque Nationale du Développement Touristique.

Note 6. Société Tunisienne des Banques.

Note 7. According to the Tunisian code of trade, article 57.

Note 8. Capital, October 1999, pp. 144-146.

Note 9. According to the method of Net Asset Value (NAV).

Note 10. Million Tunisian Dinars.

Note 11. Tunisian Dinars.

Note 12. $0,64=14,32 / 22,5$.

Note $13.0,41=9,12 / 22,5$.

Note 14. This question can be answered only in short and mid runs because the long run requires a significant number of years after merger, i.e. after 2001.

Note 15. Arab Tunisian Bank.

Note 16. Banque de l'Habitat.

Note 17. Banque Internationale Arabe de Tunisie.

Note 18. Banque du Sud.

Note 19. Banque de Tunisie.

Note 20. Union Bancaire pour le Commerce et l'Industrie.

Note 21. Union Internationale des Banques.

Note 22. Capital Asset Pricing Model.

Note 23. Market Model.

Note 24. Tunisian Stock Exchange.

Note 25. Autoregressive Conditional Heteroscedasticity.

Note 26. Generalized Autoregressive Conditional Heteroscedasticity.

Note 27. Among the other forms of evaluation of mergers appear the studies using questionnaires (less adapted because of the systematic deviations of the answers), and the case studies (are not revealing general situation). 
Table 1. Number of brought securities

Percentage of the held capital

\begin{tabular}{|c|c|c|c|c|}
\hline & BDET & BNDT & BDET & 0,41 \\
\hline STB & 41.239 & 47.009 & STB & 0,78 \\
\hline BDET & STB & BNDT & 0,20 & BNDT \\
\hline BNDT & 32.678 & 181.939 & STB & 3,03 \\
\hline
\end{tabular}

Source: BNA Capitaux -Service Recherche et Analyse-

Table 2.

\begin{tabular}{|l|l|l|l|}
\hline Company & STB & BDET & BNDT \\
\hline CTKD & 0,92 & 2,01 & 5,71 \\
\hline STICODEVAM & 2,7 & 2,7 & 2,7 \\
\hline Maison du banquier & 13,7 & 3,47 & 1,65 \\
\hline SPPI & 6,25 & 16,25 & 2,08 \\
\hline SIDCO & 5 & 14,1 & 9,86 \\
\hline Société Touristique "Ain Draham" & 15 & 15 & 19,8 \\
\hline
\end{tabular}

Source: Idem.

Table 3. Exchange parity BDET-STB

\begin{tabular}{|l|l|l|}
\hline & STB & BDET \\
\hline Number of shares & 16.000 .000 & 10.000 .000 \\
\hline $\begin{array}{l}\text { Bank value following the evaluation (Note 9) } \\
\text { in MTD (Note 10) }\end{array}$ & 360,1 & 143,2 \\
\hline Bank value/share in TD (Note 11) & 22,5 & 14,32 \\
\hline
\end{tabular}

Source: BNA Capitaux - Service Recherche et Analyse- Report of the Extraordinary General Meeting (EGM) of the STB, held on the 4/11/2000.

Table 4. Exchange parity BNDT-STB

\begin{tabular}{|c|c|c|}
\hline & STB & BNDT \\
\hline Number of shares & 16.000 .000 & 6.000 .000 \\
\hline $\begin{array}{c}\text { Bank value following the evaluation (in } \\
\text { MTD) }\end{array}$ & 360,1 & 54,7 \\
\hline Bank value/share (in TD) & 22,5 & 9,12 \\
\hline
\end{tabular}

Source: Idem. 